\title{
Is therapeutic ultrasound effective in treating soft tissue lesions?
}

\author{
A BINDER, G HODGE, A M GREENWOOD, B L HAZLEMAN, D P PAGE THOMAS
}

\begin{abstract}
Of 76 patients with lateral epicondylitis, 38 were randomly allocated to receive ultrasound treatment and 38 placebo. All 76 were given 12 treatments each over four to six weeks. The conditions of 24 patients $(63 \%)$ treated with ultrasound and $11(29 \%)$ given placebo improved, the difference being significant at the $1 \%$ level. Improvement in particular clinical variables (pain score, weight lifting, grip strength) also showed an advantage for the patients given ultrasound treatment. A simple underwater radiation balance showed considerable fluctuation in ultrasonic output, and frequent checks of output were shown to be necessary.
\end{abstract}

Ultrasound enhances recovery in most patients with lateral epicondylitis.

\section{Introduction}

Since Wood and Loomis first investigated the interaction between ultrasound and living tissue, ${ }^{1}$ biological effects of the radiation have been recognised. These include enhanced blood flow, increased membrane permeability, and altered connective tissue extensibility and nerve conduction. ${ }^{2}$ Stimulation of protein synthesis with fibroblast activation has also been reported. ${ }^{3}$ All these sequelae were initially attributed to the deep thermal effects, but introduction of pulsed ultrasound largely eliminated the rise in temperature within tissues, showing non-thermal effects also to be present. ${ }^{4}$

The effectiveness of ultrasound remains unproved. Reports have claimed its value in treating tennis elbow, ${ }^{5}$ painful shoulder, ${ }^{6}{ }^{7}$ and other conditions, ${ }^{2}$ but the failure to randomise treatment and the lack of controls have cast doubt on their conclusions. In the few studies to include a control group ${ }^{8}$ beneficial results were less pronounced. Dyson et al, however, using control groups, showed enhanced tissue regeneration in an animal model ${ }^{4}$ and improved healing of varicose ulcer in man. ${ }^{10}$

We chose tennis elbow (lateral epicondylitis) as a model for study as it is common, its clinical diagnosis is simple, and the lesion is discrete, localised, and superficial. Ultrasound, by its ability to cross myofascial planes and concentrate near bone, ${ }^{11}$ offers further theoretical advantages.

\section{Patients and methods}

Seventy six patients suffering from lateral epicondylitis (table I) of at least one month's duration were included in the study. Patients with local arthritis of the elbow (clinical or radiological), generalised polyarthritis, or neurological abnormality in the affected arm were

Addenbrooke's Hospital, Cambridge CB2 2QQ

A BINDER, MB, MRCP, honorary senior registrar and research fellow A M GREENWOOD, MCSP, senior physiotherapist

B L HAZLEMAN, MA, FRCP, consultant rheumatologist

D P PAGE THOMAS, MB, FRCPATH, honorary consultant rheumatologist

Department of Physiotherapy, Newmarket Hospital, Newmarket, Suffolk

G HODGE, MCSP, superintendent physiotherapist

Correspondence and requests for reprints to: Dr B L Hazleman. excluded. Patients who had had a single steroid injection were included if symptoms had persisted for at least one month.

Thirty nine patients $(51 \%)$ attributed symptoms to a specific cause or activity-for example, housework (11 patients), working with tools (nine patients), lifting or carrying heavy weights (eight patients), and sport or hobbies (seven patients). Only four cases had followed trauma to the elbow. Thirty patients were housewives or domestic workers, 25 were sedentary workers or unemployed, and 21 were manual or tool workers.

The ultrasound machine that was used in the study continued to be used for routine physiotherapy. The machine was standardised initially and then every month thereafter on a master balance. Output was also checked before each treatment session on a simple underwater radiation balance (fig 1) constructed for this purpose. ${ }^{12}$ An on/off key introduced into the transducer circuit allowed mock insonation to be given to a placebo group without affecting the normal ultrasonic output when the key was turned to on.

Statistics-The $\chi^{2}$ test with Yates's correction and the Wilcoxon rank sum test were used to analyse the objective outcome and the rate of recovery.

Treatment-Treatment was "pulsed" with an on to off ratio of one to four and a frequency of $1.0 \mathrm{MHz}$. It was given in contact, using Electro Medical Supplies' ultrasonic coupling medium. The space averaged intensity was increased from 1 to $2 \mathrm{~W}$ per $\mathrm{cm}^{2}$ and treatment time from five to 10 minutes during the course of treatment. Twelve treatments were given (two to three per week) over four to six weeks. A therapist not taking part in giving treatment randomly allocated patients to receive ultrasonic treatment or placebo according to a prearranged schedule. She also set the transducer switch accordingly before each treatment session so that the patient, medical assessor, and primary therapist were unaware of the treatment groups.

Patients were reviewed fortnightly while receiving treatment. Follow up continued for at least one further month before patients were discharged or, if symptomatic, offered alternative treatment.

Clinical assessment-At each visit clinical assessment included: (1) determining a pain score using a $10 \mathrm{~cm}$ horizontal analogue scale; (2) noting pain (0-3) induced by resisted wrist dorsiflexion $(0=$ no pain, $1=$

TABLE I-Clinical details of patients with tennis elbow

\begin{tabular}{lcc}
\hline & \multicolumn{2}{c}{ Patients receiving: } \\
\cline { 2 - 3 } & $\begin{array}{c}\text { Ultrasound } \\
(\mathrm{n}=38)\end{array}$ & $\begin{array}{c}\text { Placebo } \\
(\mathrm{n}=38)\end{array}$ \\
\hline $\begin{array}{l}\text { No of women } \\
\text { Mean (range) age (years) }\end{array}$ & 25 & 23 \\
$\begin{array}{l}\text { No with dominant arm affected } \\
\text { Mean (range) duration (months) }\end{array}$ & $44 \cdot 1(29-59)$ & $42 \cdot 4(29-65)$ \\
29 & $4 \cdot 8 \stackrel{(1-12)}{27}$ & $4 \cdot 3 \stackrel{(1-12)}{(12)}$ \\
\hline
\end{tabular}

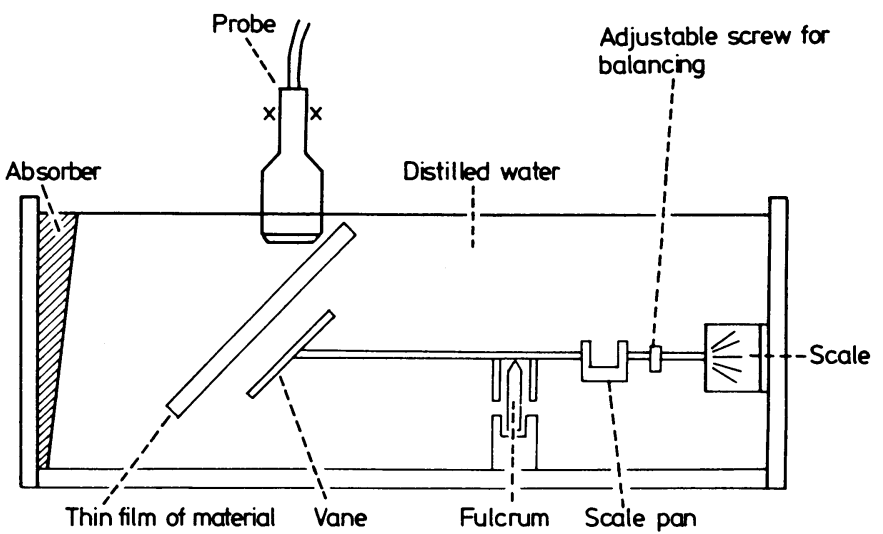

FIG 1-Simple underwater radiation balance. 
mild pain but normal power, $2=$ moderate pain and reduced power, $3=$ severe pain and absent power); (3) a weight test (0-3) to assess ability to lift weights of $1.8,0.90$, and $0.45 \mathrm{~kg}(4,2$, and $1 \mathrm{lb})$ with elbow extended and forearm pronated; (4) a test of grip strength using a $300 \mathrm{~mm} \mathrm{Hg}$ spring coil gauge attached to a rubber bag preset to $30 \mathrm{~mm} \mathrm{Hg}$. An average of three estimations were taken and recordings made with the elbow both flexed and extended. After completing treatment and during further follow up patients were asked to assess the results of treatment. The medical assessor also judged the outcome. A satisfactory outcome on examination was judged as full functional recovery with no more than a minor ache or slight tenderness, or both, remaining. The end point of the study was discharge, withdrawal, or alternative treatment. All patients, however, either were re-examined or completed a postal questionnaire at one year after inclusion in the study as part of a larger assessment of the natural history of lateral epicondylitis. ${ }^{1314}$

\section{Results}

Objective outcome-Twenty four patients treated with ultrasound $(63 \%)$ and 11 who had received placebo $(29 \%)$ showed a satisfactory outcome on objective testing both at the end of treatment and during further follow up. Contingency table analysis showed that the difference between the groups was significant ( $\chi^{2}$ with Yates's correction $=7.63 ; \mathrm{p}<0.01$ ).

Subjective outcome-Six patients (two given ultrasound treatment and four given placebo) reported the outcome, immediately after completing treatment, to be satisfactory despite persistent disability on objective assessment. Review one month later confirmed an unsatisfactory result in five of the six patients.

Analysis of variables-The two treatment groups showed no significant differences in the mean severity of any of the clinical variables at presentation. Comparisons of the rate of recovery from time 0 to each follow up visit (Wilcoxon's rank sum tests), however, confirmed a significant advantage (fig 2) for the ultrasound over the placebo group. Figure 2 shows the reduction in the pain score, pain on resisted wrist dorsiflexion, pain on weight test, and the improvement in grip strength in flexion and extension in the two groups. The importance of defining clearly the position of the arm when performing serial assessment of the clinical variables was shown by the considerable differences in grip strength when tested with the elbow flexed and the forearm supinated and with the elbow extended and the forearm pronated. The mean grip strength in all the patients at presentation was $58 \mathrm{~mm} \mathrm{Hg}$ better with the elbow flexed than with it extended. By the end of the controlled study the advantage with the elbow flexed was still $28 \mathrm{~mm} \mathrm{Hg}$ in the patients treated with ultrasound and $39 \mathrm{~mm} \mathrm{Hg}$ in the placebo group. The duration of symptoms at presentation, dominance of the affected $\mathrm{arm}$, and treatment given before referral did not influence the outcome, but patients who responded to mock insonation had less severe symptoms at presentation than those responding to ultrasound.

Reliability of the ultrasound machine-Fluctuation in the ultrasonic output was detected in the study machine when it was subjected to checks on the underwater radiation balance before treatment. Treatment had to be delayed for repairs to the ultrasound machine on two occasions when there was no output and on a further four occasions when the radiation was considerably reduced.

Further treatment-Forty one patients (14 given ultrasound treatment and 27 given placebo) still showed an unsatisfactory outcome at the end of the controlled study and were offered ultrasound (some placebo group patients) or steroid injections, or both (table II). Eight patients either withdrew still complaining of severe disability or required surgery to the elbow; of these, four were housewives, two domestic workers, and two manual workers.

Review at one year-All the patients were re-examined or completed a postal questionnaire at one year. A much lower incidence of recurrence of severe pain (table III) was noted in the patients who responded to ultrasound than those who required steroid injections. Minor or intermittent pain in the elbow was still present in over half the patients.

\section{Discussion}

Our findings confirm that ultrasound enhances recovery in patients with lateral epicondylitis ${ }^{5}$ but in only $63 \%$ of cases. By serial assessment of clinical variables we were able to confirm that the rate of recovery was significantly better in treated patients than the placebo group, and later review suggested a lower incidence of recurrence in the patients who responded to ultrasound. Eleven $(29 \%)$ of the patients in the placebo group recovered without any other treatment. This
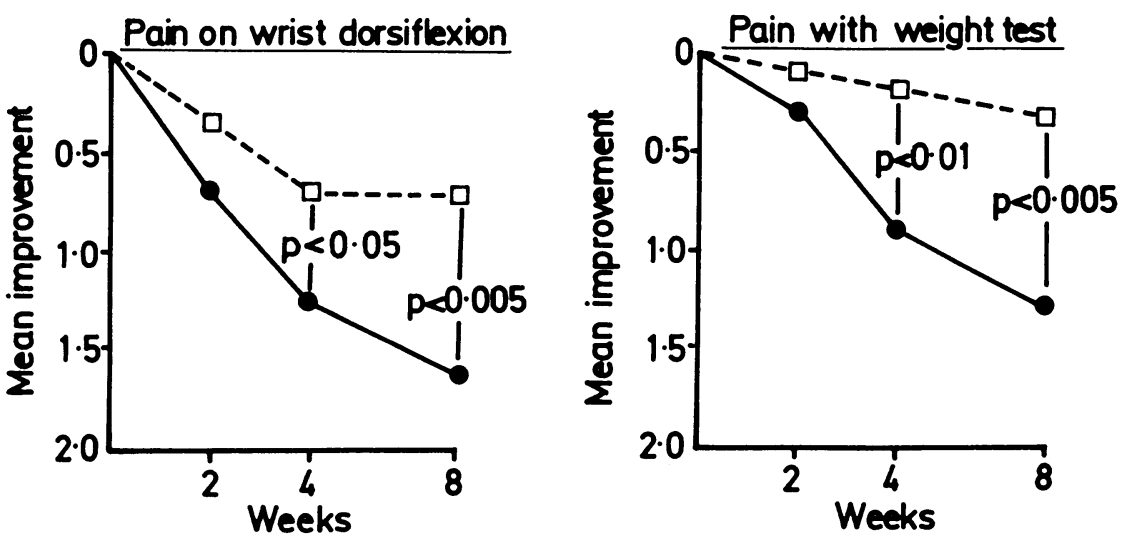

Ultrasound group

Placebo group $\quad$ -
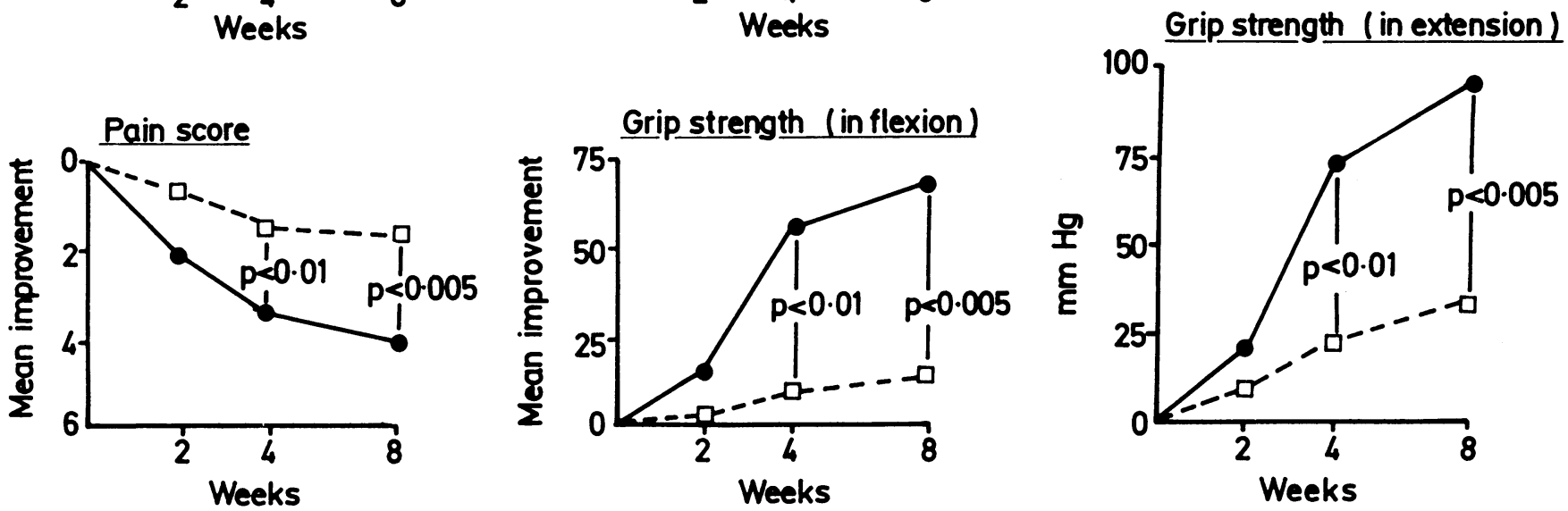

FIG 2-Mean improvement in clinical variables from time 0 in 38 patients treated with ultrasound and 38 given placebo. 
TABLE II-Outcome in patients with an unsatisfactory initial outcome

\begin{tabular}{lcc}
\hline & \multicolumn{2}{c}{ Patients who had received: } \\
\cline { 2 - 3 } & $\begin{array}{c}\text { Placebo } \\
(\mathbf{n}=27)\end{array}$ & $\begin{array}{c}\text { Ultrasound } \\
(\mathrm{n}=14)\end{array}$ \\
\hline Healed with ultrasound & 8 & 11 \\
Healed with injections & 7 & 1 \\
Healed with ultrasound and injection & 7 & 2 \\
Withdrew while symptomatic & 3 & \\
Referred for surgery to elbow & 2 & \\
\hline
\end{tabular}

TABLE III-Overall outcome at discharge and at review after one year

\begin{tabular}{lcc}
\hline & \multicolumn{2}{c}{ After one year } \\
\cline { 2 - 3 } & Satisfactory & Unsatisfactory \\
\hline $\begin{array}{c}\text { Satisfactory after: } \\
\quad \text { Placebo }(\mathrm{n}=11)\end{array}$ & 6 & 5 \\
$\begin{array}{c}\text { Ultrasound with or without } \\
\text { placebo }(\mathrm{n}=32)\end{array}$ & 29 & 3 \\
$\begin{array}{c}\text { Steroid injection with or without } \\
\text { ultrasound or placebo, or both } \\
(\mathrm{n}=25)\end{array}$ & 13 & 12 \\
$\begin{array}{c}\text { Unresolved or refused further } \\
\text { treatment }(\mathrm{n}=8)\end{array}$ & $2 *$ & $6+$ \\
\hline
\end{tabular}

* Reduced to one patient after surgery.

* Reduced to one patient after surgery.
+ Reduced to two patients after surgery.

may reflect the benefits of careful supervision, increased rest, and natural remission but may also have resulted from the massage effect of the transducer head over the affected area during mock insonation.

Subjective patient assessment immediately after the completion of treatment has usually been used to determine the efficacy of treatment. We, however, found a definite discrepancy between the subjective and objective assessments. Review four to six weeks later showed better agreement. Repetitive activity, especially housework, often precipitated onset, and failure to rest from this activity resulted in poor response. Although Dyson et al, using an animal model, ${ }^{4}$ suggested that maximum benefit could be obtained from starting treatment as early as possible, we could detect no advantage in patients who presented early.

Clarke and Stenner ${ }^{15}$ and Allen and Battye ${ }^{16}$ noted considerable changes in ultrasonic output with time. Using a simple underwater balance, we confirmed these changes in radiation output emphasising the need for frequent assessment. Ultrasound is time consuming to patient and therapist, and further controlled studies in other conditions are necessary. Previously we have shown that clinical and thermographic changes reflect severity of lateral epicondylitis. ${ }^{14}$ It therefore is a useful model for the assessment of therapeutic measures such as ultrasound.

\section{References \\ 1 Wood RW, Loomis AL. The physical and biological effects of high-frequency sound waves of great intensity. London, Edinburgh, Dublin philosophical Magazine and fournal of Science 1927;4:417-36. \\ Lehmann JF, Warren CG, Scham SM. Therapeutic heat and cold. Clin Orthop \\ 3 Harvey W, Dyson $M$, Pond JB, Grahame R. The stimulation of protein synthesis in human fibroblasts by therapeutic ultrasound. Rheumatol Rehabil 1975;14: \\ Dyson $\mathrm{M}$, Pond JB, Joseph J, Warwick $\mathrm{R}$. The stimulation of tissue regeneration by means of ultrasound. Clin $S_{c i} 1$ 1968;35:273-85. \\ Aldes $\mathrm{JH}$. Ultrasonic radiation in the treatment of epicondylitis. General Pructitioner 1956;13:89-96. \\ 6 Lehmann JF, Erickson DJ, Martin GM, Krusen FH. Comparison of ultrasonic and microwave diathermy in the physical treatment of periarthritis of the shoulder. Archives of Physical Medicine 1958;35:627-38. \\ 7 Munting E. Ultrasonic therapy for painful shoulders. Physiotherapy 1978;64: \\ 8 Flax $\mathrm{HJ}$. Ultrasound treatment of peritendinitis calcarea of the shoulder. Am F Phys Med 1964;43:117-24 \\ Mueller EE, Mead S, Schultz BF, Vaden MR. Symposium on ultrasonics; a placebo-controlled study of ultrasound treatment for periarthritis. Am $\mathcal{F}$ Phys Men $M$ Franks C,

 \\ .232-6. \\ 11 Lehmann JF, De Lateur BJ, Warren CG, Stonebridge JB. Healing produced by ultrasound in bone and soft tissue. Archives of Physical Medicine 1967:48: 397-401. \\ 12 Lunt MJ, Ashley B. A simple radiation balance for measuring ultrasonic power. 7 Med Eng Technol 1979;3:194-7. \\ 13 Binder AI, Hazleman BL. Lateral humeral epicondylitis-a study of natural history and the effect of conservative therapy. Brf Rheumatol 1983;22:73-6. der A, Parr G, Thomas DP, Hazleman B. A clinical and thermographic study of lateral epicondylitis. Br f Rheumatol 1983;22:77-81. \\ 15 Clarke GR, Stenner L. Use of therapeutic ultrasound. Physiotherapy 1976;62 : \\ 16 Allen KGR, Battye CK. Performance of ultrasonic therapy instruments. Physiotherapy 1978;64:174-9. \\ (Accepted 13 November 1984)}

\title{
Assessment of dermal glyceryl trinitrate and isosorbide dinitrate for patients with angina pectoris
}

\author{
PETER J B HUBNER, PETER R M JONES, IAN A R GALER
}

\begin{abstract}
Dermal nitrate preparations are claimed to be useful in the treatment of angina, as their slow absorption bypassing the liver leads to a sustained action. Ten patients with angina were exercised on a treadmill after dermal application of $16.64 \mathrm{mg}$ glyceryl trinitrate or $100 \mathrm{mg}$ isosorbide dinitrate or placebo. Exercise duration was significantly increased at one and three hours for both
\end{abstract}

Department of Cardiology, Groby Road Hospital, Leicester LE3 9QE PETER J B HUBNER, MB, MRCP, consultant cardiologist

Department of Human Sciences, Loughborough University of Technology, Leicestershire LE11 3TU

PETER R M JONES, MSC, PHD, reader in human functional anatomy

IAN A R GALER, BSC, MSC, lecturer in ergonomics

Correspondence and requests for reprints to: Dr P J B Hubner. nitrate preparations but not at six hours after application. The calculated workload achieved was significantly increased $(p<0.01)$ at one and three hours for both preparations and at six hours $(p<0.05)$ for isosorbide dinitrate. Headaches were common with glyceryl trinitrate cream. The dermal nitrate preparations studied had a duration of antianginal action similar to that of oral nitrate tablets.

Aside from their value when the oral route cannot be used or absorption may be delayed, dermal nitrate preparations have no advantage over oral preparations for angina pectoris.

\section{Introduction}

When glyceryl trinitrate and isosorbide dinitrate are taken by mouth they are absorbed by the intestines and pass to the liver, where they are partially broken down. This "first pass" metabolism limits the duration of action of oral nitrates," though 